\title{
Disparity of outcomes: the limits of modeling amyotrophic lateral sclerosis in murine models and translating results clinically
}

\author{
Pierre Zwiegers ${ }^{1,3}$, Christopher A Shaw ${ }^{1,2,3}$ \\ ${ }^{1}$ Experimental Medicine Program; ${ }^{2}$ Graduate Program in Neuroscience; ${ }^{3}$ Department of Ophthalmology \\ and Visual Sciences, University of British Columbia, Canada.
}

\begin{abstract}
Amyotrophic lateral sclerosis (ALS) is a devastatingly progressive neurodegenerative disorder with multiple underlying etiological factors contributing to disease pathogenesis. Despite intensive research efforts and therapeutic development, disease presentation in ALS remains largely intractable to intervention. To date, the most common rodent model used in preclinical drug development accounts for a small proportion of the affected patient population and is predicated upon the significant overexpression of a mutant form of the human antioxidant protein, superoxide dismutase 1 (mSOD1). After more than 50 clinical trials, there is an alarming paucity of positive outcomes at the clinical level of ALS therapeutics with strong supporting pre-clinical data in mSOD1 models. Potential reasons for the negative clinical results are multifactorial in nature and include an overly reductionist model system that is heavily influenced by individual transgene level variation, as well as attempting to widely apply findings derived from a model of specific genetic causality to a patient population where the majority of cases are of unknown etiology. With such a tremendous disease burden and a lack of therapeutic options, it is critical that the research community re-evaluate the dependence on mSOD1 pre-clinical models as the gold standard prior to translating findings at the clinical level. Here we briefly review both the clinical and pre-clinical findings of select therapeutics, discuss the limitations of pre-clinical mSOD1 models, and suggest future stratagems that could aid in the clinical translation of efficacious therapeutic agents.
\end{abstract}

Received: 21 July 2015; Accepted after revision: 13 August 2015; Published: 24 August 2015.

Author for correspondence: Christopher A Shaw, Department of Ophthalmology and Visual Sciences, University of British Columbia, Canada. E-mail: cashawlab@gmail.com

How to cite: Zwiegers P, Shaw CA. Disparity of outcomes: the limits of modeling amyotrophic lateral sclerosis in murine models and translating results clinically. Journal of Controversies in Biomedical Research 2015; 1(1):4-22. Doi: http://dx.doi.org/10.15586/jcbmr.2015.3

\section{Introduction}

Amyotrophic lateral sclerosis (ALS) is a fatal, adult-onset, multifactorial, and progressively neurodegenerative disorder of motor neurons within the brainstem and spinal cord. Due to the progressive nature of the disease, symptoms worsen temporally as motor neurons deteriorate and muscle atrophy becomes increasingly established.
Severe respiratory complications typically culminate in death 2-5 years following diagnosis. In North America, the incidence rate of ALS is approximately 2 per 100,000 and is expected to increase with an aging demographic (1). To date, more than 20 genetic mutations have been identified in familial forms of ALS (fALS); accounting for 
approximately $5 \%$ of all cases $(2,3)$. The most common underlying genetic causes of fALS pathogenesis include the recently characterized C9orf72 intronic hexanucleotide repeat expansion, as well as mutations in the genetic loci for the $\mathrm{Cu} / \mathrm{Zn}$ superoxide dismutase 1 enzyme (SOD1), TAR DNA binding protein (TARDBP), and Fused in Sarcoma (FUS) RNA-binding protein (Figure 1; reviewed in 3, 4). Implicated in up to $20 \%$ of all fALS cases, more than 180 toxic-gain-of-function mutations in the SOD1 gene has been described throughout all exonic sequences (Figure 2; 3, 5). The vast majority of ALS patients (95\%), however, suffer from a sporadic form of the disease (sALS) in which unknown etiological factors are causal in inducing the disease $(4,6)$.

From a clinical and pathological standpoint, both forms of ALS (SOD-1 fALS and sALS) have primarily been considered to be virtually indistinguishable, since it is thought that different initiating events ultimately converge to induce a similar mechanistic cascade of disease progression $(7,8)$. This has led to the notion that if researchers can dissect and understand the defective pathway(s) identified in the context of genomic SOD1 abnormalities, that this knowledge can be translated to sporadic forms of the disease and thus aid in therapeutic development.

After more than two decades of work, various SOD1 genetic anomalies have been identified and actively studied in rodent models. An overarching pathogenic mechanism of action, however, remains elusive and the majority of therapeutic agents investigated have failed to yield positive outcomes when translated to the clinical level. Further challenging this reductionist viewpoint are neuropathological findings which suggest that the phenotypic expression of ALS may be consequent to heterogeneic pathologies affecting the central nervous system (CNS). For instance, by utilizing antibodies specific for labeling misfolded conformations of the SOD1 protein, some groups have demonstrated positive immunolabeling in fALS cases, a finding not always recapitulated in sALS (9-12). Similarly, pathological TDP-43 positive cytosolic inclusions common in sALS have not been described in mutant SOD1-linked fALS (13); a finding which is not always observed in mutant SOD1 models $(14,15)$. Taken together, these outcomes may signify diverse pathological cascades which ultimately present with the typical ALS phenotypic end state.

Historically, mutations within the SOD1 locus were first associated with the clinical presentation of ALS, and were instrumental in developing the initial animal models that have been employed in pre-clinical research (16-18). After more than 50 randomized control trials testing various therapeutic agents which had a positive effect in preclinical models, Riluzole remains the only FDA-approved drug available to the affected patient population (19).

What follows is a brief review of the common mutant SOD1 (mSOD1) fALS murine models, the initial promising pre-clinical results, as well as the resultant outcomes of select clinical trials. We will then shift our attention to a discussion regarding the future applicability of these model systems in pre-clinical research studies.

\section{Murine models of familial ALS}

In the mid-nineties with the discovery that mutations in the antioxidant $\mathrm{Cu} / \mathrm{Zn}$ superoxide dismutase 1 (SOD1) gene locus was inheritable and linked to an ALS phenotype, there was renewed hope in the research community that a treatment was on the verge of being developed. To aid in therapeutic discovery, a murine model overexpressing a clinically-relevant mutant form of the human SOD1 enzyme with a glycine to alanine substitution at codon 93 (G93A) was created $(17,20-22)$. This result was soon followed by the development of mice overexpressing a variety of missense mutations in the SOD1 locus including G37R (18), D90A (23), G85R (24), and several other genomic abnormalities (25, 26). Due to the random genomic integration of the transgene, various lines of each mutation were established; each carrying the mutant gene to a varying degree and exhibiting a severity of disease that was 


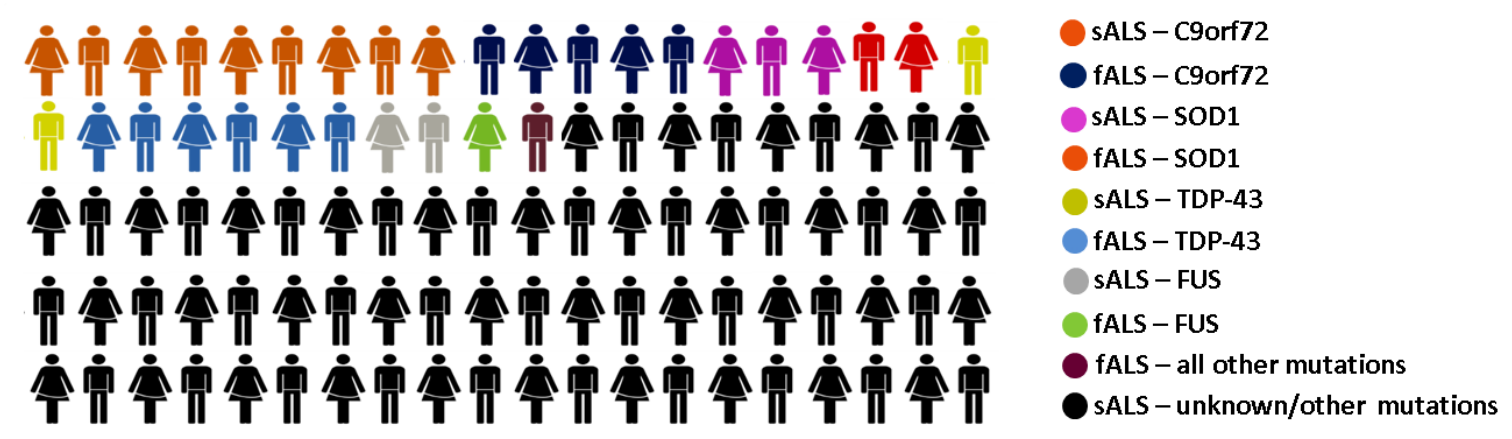

Figure 1. Graphical representation of the approximate frequencies of familial and sporadic ALS cases in the overall affected patient population, rounded to the nearest integer. Frequency of causes are expressed per 100 ALS patients and do not account for sex differences. Infographic generated from the upper frequency limit summarised in (3).

highly dependent on the number of integrated transgenes (see Table 1 for the G37R and G93A mSOD1 models). These animal models were instrumental in delineating that the disease outcome was not a result of reduced dismutase activity, but due to a so-called "toxic-gain-offunction" property inherent to the mutant form of human SOD1 (22). More recent evidence, however, suggests that a loss of SOD1 activity may also contribute to disease presentation (27).

Prototypically, the G93A mSOD1 animals experience a rapidly progressive phenotypic deterioration, ultimately showing signs of hind limb paresis at approximately 150 days of age (17). On account of the rapid and robust expression of the disease phenotype in these animals, the G93A model has become the most widely used system in assessing putative therapeutic agents (28). Neuropathologically this model shows neuronal cell loss within the spinal cord as well as evidence for both astrocytic and microglial proliferation; thus recapitulating some key features inherent to clinical ALS cases $(20,29-32)$. Within this context, these in vivo mSOD1 models have provided a glimpse into an aspect of the purported pathomechanism(s) underlying disease presentation. This was thought to underscore their utility in not only studying the inherent degenerative cascade, but also in translational therapeutic development for all forms of ALS. However, since their inception, a plethora of potential therapeutics have been tested in these models and similar positive outcomes have not been recapitulated when applied to the clinical setting. The paucity of positive clinical outcomes from therapies derived from pre-clinical studies suggest that critically re-evaluating the sole reliance on mutant SOD1 models may identify nonproductive research endeavours and accelerate therapeutic development of efficacious agents.

\section{Clinical applications derived from investigations based on murine models}

To date, various therapeutics have been investigated for the ability to attenuate and/or ameliorate the pathological disease cascade induced in $\operatorname{ALS}(19,33)$. Each of these agents addresses a unique hypothetical mechanism which is purported to play a key role in establishing the eventual disease state. Selected outcomes from both pre-clinical and clinical trials are discussed below (also see Supplementary Tables S2, S3, and S4).

\section{Riluzole}

Glutamate is a major excitatory neurotransmitter within the CNS (reviewed in 34). Once released into the synaptic cleft, glutamate relays the action potential to the downstream target neuron and the original signal is further propagated towards the target site. Under normal physiological conditions, an intricate system of neuronal and glial glutamate transporters result in the expedient endocytic uptake of extracellular glutamate, and so remove the excitatory stimulus acting on the postsynaptic cell. Increased levels of excess glutamate in the extracellular milieu will 


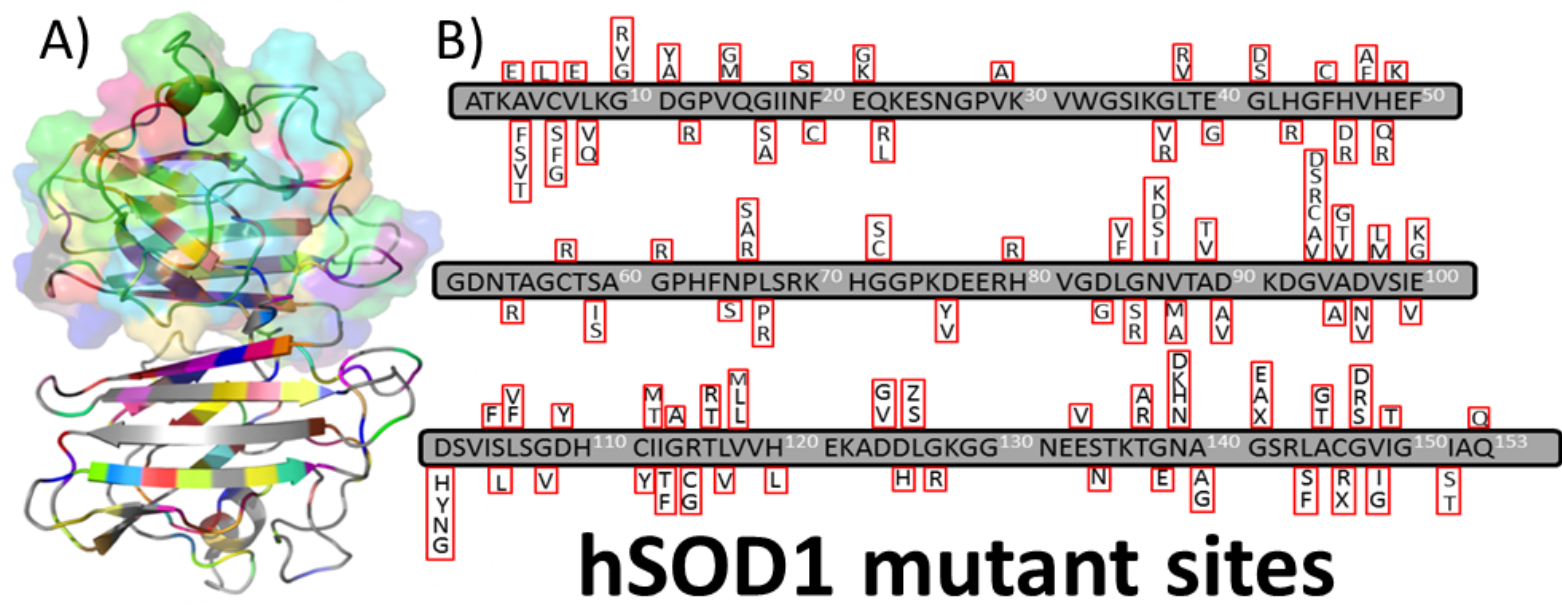

Figure 2. Distribution of hSOD1 amino acid substitutions within the monomer. A) PyMOL ${ }^{1}$ graphical visualization of the SOD1 protein identifying >150 amino acid substitutions throughout the 3D structure of the protein. B) The panel outlines the sites of substitution within the primary sequence of the polypeptide. Sites of the mutant residues depicted are derived from the ALS Online Genetic Database (5). ${ }^{1}$ The PyMOL Molecular Graphics System. Schrödinger, LLC.

result in excitotoxic activity of the postsynaptic cell due to aberrant $\mathrm{Ca}^{+}$ homeostasis within the cytosol arising from excessive membrane depolarization mediated through glutamate receptors (35). Increased cytosolic $\mathrm{Ca}^{+}$ions are compartmentalized within the mitochondrion, which can result in alterations of mitochondrial permeability, production of reactive oxygen species (ROS) and/or activating a plethora of enzymes involved in cell death pathways $(36,37)$. Preliminary evidence invoking a role for glutamate in the pathogenesis of ALS included an increase in peripheral levels (and a concomitant decease in CNS tissue) in ALS patients $(38,39)$, reduced glutamate uptake in patient-derived synaptosomes (40), and a reduction in levels of the astrocytic glutamate transporter, EAAT2 (35). Riluzole, the only approved pharmacological agent for treating ALS, has been shown to be effective in extending survival, but only by a modest 2-3 months (41). A concrete mechanism of action is yet to be elucidated; however, it appears to act on glutamate transporters to facilitate the extracellular clearance of the excitotoxic neurotransmitter (42), as well as inhibiting the presynaptic cell from releasing glutamate (43). Synergistically, both of these actions would serve to decrease the glutamate load in the extrasynaptic space and thus attenuate the proposed cellular excitotoxic effects involved in disease pathogenesis.

In contrast to the other ALS therapeutics discussed below, Riluzole treatment in the clinical setting preceded validation in the ALS animal model, but was explored based on evidence of anti-glutamatergic activity. The initial clinical study at $100 \mathrm{mg} /$ day indicated a significant improvement in overall lifespan after 12 months of treatment, a concomitant decrease in the rate of muscle deterioration, and evidence of a more efficacious effect in patients exhibiting bulbar-onset ALS (S3, S4; 44). Subsequent follow-up studies were shown to replicate the initial therapeutic effect and investigated additional secondary outcome measures. A dose-response study (50-200 $\mathrm{mg} /$ day) showed a significant improvement in survival at higher doses. However Riluzole treatment failed to significantly affect functional assessments (i.e. muscle testing, respiratory function, and subjective symptom assessment), or differentially affect limb- or bulbar-onset cases $(45,46)$. Population-based studies confirmed a positive therapeutic effect of Riluzole treatment that particularly affected bulbaronset patients. However, the overall effect in ALS patients was transient in that the survival curves were unaffected when examined in prolonged follow up studies $(47,48)$. In ALS animal models (S2), Riluzole 
treatment $(100 \mu \mathrm{g} / \mathrm{mL}$ water $)$ during the presymptomatic stage was initially shown to exert no effect on delaying the onset of disease, but did significantly extend survival by 13-15 days (49). A follow-up study showed a dose-dependent preservation of motor function, while exhibiting an identical positive effect of survival at doses of 24-44 $\mathrm{mg}$ riluzole $/ \mathrm{kg}$ body weight/day of $12-13$ days (50). The positive, but modest, clinical effect combined with an extended survival in the fALS model has solidified the notion of the clinical utility of Riluzole as a therapeutic agent in ALS, which to date, remains the only drug approved for treatment.

\section{Minocycline}

Minocycline is a lipid-soluble, semisynthetic tetracycline antibiotic that can readily penetrate the blood-brain barrier, and has been shown to exhibit antiinflammatory properties apart from its expected antimicrobial activity (51). Initial work in models of neurodegeneration had shown that treatment with the antibiotic prevented microglial activation, inhibited release of the pro-inflammatory cytokine IL$1 \beta$, and rescued primary neuronal cells from glutamate cytotoxicity $(51,52)$. Increased neuroinflammatory processes and the activation of microglia have long been suspected in the underlying pathomechanism of ALS (53). The strong preliminary data in models of neurodegeneration warranted further study in the context of ALS. Mutant SOD1 animal models (G37R or G93A) receiving minocycline either in their diet or via intraperitoneal injections during the presymptomatic phase of the disease, showed evidence of a dose-dependent delay in onset and an attenuated progression of disease (S2; 54-56). Following preliminary studies assessing the safety and tolerability of minocycline in ALS patients $(57,58)$, a randomised phase 3 clinical trial set out to test the efficacy of the treatment paradigm (S3 and 4; 59). In contrast to pre-clinical findings, oral dosage of minocycline was found to be associated with a significantly more rapid decline in functional outcome scores (as measured by the revised ALS functional rating scale), while concurrently showing evidence for a reduction in lung capacity and muscle performance. Although pre-clinical evidence showed a marked attenuation of disease presentation, similar findings were not recapitulated within the clinical setting, and treatment with minocycline seemed to exacerbate ALSrelated deterioration.

\section{Creatine}

Mitochondria are crucial in generating the intracellular energy stores required to drive biochemical processes, maintain calcium homeostasis, and play a role in regulating apoptosis (60). Murine models of SOD1-ALS show evidence of aberrant mitochondrial pathology; most notably mitochondrial swelling and vacuolization (18, 20). Functionally, in vivo model systems expressing the G93A missense mutation in the SOD1 locus showed evidence for a decrease in mitochondrial membrane potential, an increase in the concentration of cytosolic calcium ions, as well as an increased susceptibility to oxidative stress (61, 62). Clinically, ALS patients show aberrant mitochondrial pathology in that a dense aggregation of mitochondria is localized to the presynaptic terminal (63). Such dysfunction of mitochondria would ultimately perturb the energy balance of the system and contribute to cellular degeneration. Therapeutics directed at enhancing and/or stabilizing normal mitochondrial functioning was thus speculated to be of some utility in treating ALS. Creatine, generated through a biosynthetic pathway involving arginine and glycine, exists in non-phosphorylated and phosphorylated forms. Together, these biomolecules serve an important function in producing ATP at sites of high energy consumption (64, 65). Exogenously administered creatine was shown to exert neuroprotective properties through various inter-related pathways including attenuating glutamate-induced cytotoxicity (66), and directly acting as an antioxidant against reactive ion species (67). Elevated creatine levels are thought to protect mitochondrial creatine kinase from oxidative damage which inhibits the opening of the mitochondrial transition pore, and so protects against cell death $(68,69)$. Oral creatine treatment in the G93A model showed evidence of a dose-dependent increase in overall lifespan (26 days at 2\% $\mathrm{w} / \mathrm{w}$ creatine supplementation compared to 
transgenic controls), improved motor performance, and exhibited an increase in neuronal viability comparable to wild-type littermates in a cohort receiving 1\% dietary creatine (S2; 70). In the context of a lower copy number, dietary creatine $(2 \% \mathrm{w} / \mathrm{w})$ was shown to delay symptom onset by 12 days and decrease the severity of disease presentation, however, this did not correlate with a significant amelioration of motor neuron loss (71). Combinatorial approaches showed that creatine dosage supplemented with minocycline, but not Riluzole, resulted in an additive therapeutic effect with a delay in phenotypic onset and a concomitant increase in overall lifespan (71, 72). Clinically at a dose of $10 \mathrm{~g} /$ day, dietary creatine intake (for 16 months) did not positively affect survival rates or the degree of decline for a variety of clinically-relevant measures (65). A concurrent study at a lower dosage (5g/day) for six months examining a different set of outcome parameters similarly failed to establish a role for creatine in ameliorating ALS pathogenesis (73). Following a preliminary study with positive outcomes, Rosenfeld et al. set out with a larger cohort and followed patients for nine months receiving creatine at $5 \mathrm{~g} /$ day (74). As in the previous clinical trials, dietary supplementation failed to demonstrate a therapeutic benefit in multiple measures of relevance to the clinical presentation of ALS (S3 and S4). The lack of positive correlation between preclinical models and clinical trials in therapeutic outcomes of creatine treatment has halted further clinical investigation of the agent.

Limitations of clinical ALS trials and modeling disease in mouse models expressing mutant human SOD1

Having briefly reviewed the clinical outcomes of three selected therapeutic agents, it is likely that the discrepancy between pre-clinical results and clinical translation are multifactorial in nature. Mounting evidence supports a heterogeneous cascade of events that underlie the inherent pathomechanism(s) of ALS (6). Clinically, patients present with a phenotypically heterogeneous disease that can affect site of onset, rate of disease progression, upper and/or lower motor neuron involvement, and whether the phenotype is strictly behavioural or elicits some form of cognitive impairment (75). It is probable that inadequate stratification of the patient population in terms of phenotypic variability (and perhaps yet unknown genetic and environmental causal factors) could undermine robust clinical outcomes, since any specific treatment effects may only be applicable to a subset of ALS patients $(19,76)$.

The theoretical utility of animal models is in their ability to mimic the underlying disease cascade and thus act as a platform for therapeutic development. A model system should be representative of the patient population as a whole so that any preclinical drug development should be applicable when translated clinically. In the case of ALS, there is roughly a global prevalence rate of 4-7 per 100, 000 population; thus around half a million patients would be affected world-wide (1). Familial ALS cases due to mutant SOD1 loci would then account for approximately 500010,000 patients. Pre-clinical development based solely on a model of mutant SOD1 thus has the potential to greatly impede translational applicability since (i) such a small percentage of patients that comprise the clinical trial will be carrying a mutant copy of the SOD1 gene, and (ii) logistically enrolling SOD1-affected fALS patients in a trial of sufficient power to properly test a developed therapy would prove daunting.

Further, as is evidenced in this brief review, there is limited proof for translational applicability of therapeutics developed in mSOD1 models of ALS: a caveat not restricted to neurodegenerative disease research. Generally a positive pre-clinical effect has less than a $40 \%$ chance of recapitulating a similar clinical outcome (77), with some animal models not even accurately portraying the inherent disease pathomechanism(s) (78).

Limited independent validation studies, publication bias and deficits in good experimental design may also account for some of the discrepancy in outcomes between clinical and pre-clinical mSOD1 
Table 1. Timing of the progressively degenerative phenotype in mSOD1 murine models is highly dependent on the degree of mutant protein expression.

\begin{tabular}{|c|c|c|c|c|}
\hline \multirow[b]{2}{*}{ Genetic modification [line] } & \multirow{2}{*}{$\begin{array}{l}\text { \# of gene } \\
\text { copies }\end{array}$} & $\begin{array}{l}\text { Relative SOD1 } \\
\text { Protein Levels }\end{array}$ & & \multirow{2}{*}{$\begin{array}{l}\text { Mean age at } \\
\text { death (d) }\end{array}$} \\
\hline & & $\begin{array}{l}\text { (Human/mouse) } \\
\text { spinal cord }\end{array}$ & $\begin{array}{l}\text { Mean ALS } \\
\text { onset (d) }\end{array}$ & \\
\hline $\begin{array}{l}\text { hSOD1 G93A [G1] } \\
(17,20,21,25)\end{array}$ & 18 & n.d. & $90-120$ & $153-185$ \\
\hline $\begin{array}{l}\text { hSOD1 G93A [G1H] } \\
(22,25,85)\end{array}$ & 25 & n.d. & 90 & 136 \\
\hline $\begin{array}{l}\text { hSOD1 G93A [G1L] } \\
\text { (86) }\end{array}$ & 13 & n.d. & 200 & 251 \\
\hline $\begin{array}{l}\text { hSOD1 G93A [G5/G5] } \\
\text { (80) }\end{array}$ & 10 & n.d. & 300 & $>400$ \\
\hline $\begin{array}{l}\text { hSOD1 G93A [G20] } \\
(17,21)\end{array}$ & 1.7 & n.d. & n.d. & $>300$ \\
\hline $\begin{array}{l}\text { hSOD1 G37R[42] } \\
(1,6)\end{array}$ & n.d. & 12.3 & 106-121 & $155-176$ \\
\hline $\begin{array}{l}\text { hSOD1 G37R[9] } \\
\text { (18) }\end{array}$ & n.d. & 6.2 & $152-183$ & n.d. \\
\hline $\begin{array}{l}\text { hSOD1 G37R[106] } \\
\text { (18) }\end{array}$ & n.d. & 5.3 & $167-228$ & n.d. \\
\hline $\begin{array}{l}\text { hSOD1 G37R[29] } \\
(18,102,103)\end{array}$ & n.d. & 5 & $183-243$ & $348-380$ \\
\hline $\begin{array}{l}\text { hSOD1 wild-type [76] } \\
\text { (18) }\end{array}$ & n.d. & 10.5 & $\begin{array}{l}\text { None by } \\
548 d\end{array}$ & n.d. \\
\hline
\end{tabular}

n.d. = not determined

studies (28). Furthermore, as Scott et al. poignantly discuss, failing to control for specified biological factors in ALS models has likely resulted in the measurement of chance variability (i.e. "noise"), and has thus resulted in false positive results (79). To underscore the importance of these variables, an optimized study paradigm investigating the efficacy of Riluzole, minocycline, or creatine were unable to replicate the positive pre-clinical outcomes previously discussed (79).

In short, due to the complex interplay of etiological factors, effectively modeling ALS has proven to be quite challenging. Thus, the discrepancy in translating therapeutics clinically is likely multifactorial in nature and will be the focus of the remaining discussion. Of primary concern here is how well the in vivo model mimics clinical ALS, impediments hindering replicability between pre-clinical studies, as well as the importance of species differences in drug metabolism.
Models representative of clinical ALS

Focusing on the original line of G93A mSOD1 animals with the greatest number of transgene integrations (G1), neuropathological changes are of a progressively degenerative nature $(17,20$, 21). At the outset, vacuolar degeneration is observed within motor neurons, but with time, alongside a marked reduction of neuronal cell bodies, pathological vacuoles are present within the surrounding neuropil with a marked deterioration of the anterior horn. Evidence for vacuolar degeneration in animals highly expressing the mutant G93A SOD1 locus does not reflect the reality of end-state pathology in human cases, and has been suggested to be a toxic artefact arising from the transgene being significantly overexpressed (21). Thus, it is possible that the marked overexpression of the mutant transgene results in a more severe disease pathology which may not reliably measure a positive or negative clinical outcome for translational purposes. 
Within the context of an accelerated disease cascade, it is probable that failed therapeutic agents at the pre-clinical stage may have had some clinical utility in the protracted form of human disease. However, without strong pre-clinical data in these progressive models, candidate therapeutics will not be promoted to the clinical trial stage.

Expression of the aberrant phenotype in SOD1 fALS models are driven by the significant overexpression of the mutant hSOD1 locus (Table 1). In stark contrast, familial forms of the disease (SOD1-linked fALS) are inherited mostly in an autosomal dominant manner and thus present with ALS in the context of one aberrant copy. Transgenic lines carrying significantly fewer copies of various gain-of-function mutations do not develop disease after prolonged observation $(17,18)$, or give rise to a significantly protracted disease course (80). For instance the SOD1A4V strain of mice carry the most common SOD1 mutation found in North America (81), yet fail to recapitulate the requisite phenotypic correlates of disease (17). This is primarily thought to be a consequence of decreased transgene expression levels. Of the two A4V lines developed, the line expressing the mutant protein to a higher degree $(20 \%$ greater than the lower expressing line) was shown to exhibit an affected phenotype only when crossbred with a line overexpressing wild-type hSOD1 suggesting that a threshold level of mutant SOD1 needs to be exceeded prior to phenotypic onset (82).

An additional impediment in utilizing the model to predict clinical efficacy is in the timing of drug administration. Typically the timing of drug delivery in these models is prior to phenotypic onset and thus provides a wide therapeutic window for the effect to be realized (S2). In lieu of biomarkers which specifically gauge the onset and progression of the disease, a typical therapeutic intervention initiated in the clinic will only be administered following symptom onset; most notably at a stage of the disease when marked neuronal cell loss has already occurred. Due to the intractable and rapidly progressive nature of ALS, it should not be surprising that many promising pre-clinical therapeutics have not been able to attenuate and/or ameliorate the disease when initiated at an advanced stage when translated to the clinic.

Impediments to replicability between preclinical studies

The literature is rife with studies exemplifying the relationship between mutant hSOD1 transgene levels incorporated into the genome and the degree of phenotypic severity. Our recent experience with the G37R model underscores this dilemma in that we had generated a colony of animals from commercial breeders with an uncharacterized drop in copy number. As expected, these presented with a concomitant increase in lifespan and delay in disease progression (83). Transgene level variation can arise due to meiotic recombination. In the G93A mSOD1 model, this is relatively infrequent with recombination accounting for transgene fluctuations in approximately $3 \%$ of the progeny produced (84). Due to random meiotic events, the original G93A G1 line has spawned two additional sub-lines with either a $40 \%$ expansion (25 copies) or $30 \%$ retraction (13 copies) of the mutant hSOD1 locus; each showing variations in phenotype severity on account of altered transgene expression levels $(85,86)$.

Experimentally, variations in transgene dosage are detrimental to research efforts. First, small colonies are likely to be adversely impacted and would serve limited applicability in replication studies. Second, undetected fluctuations in individual copy number will give rise to animals exhibiting varied phenotypic expression of disease severity, and thus respond differently to therapeutic intervention. Should an experimental cohort by chance be comprised of outliers with either higher/lower copy numbers, a tested therapeutic effect may be primarily a consequence of disease severity linked to transgene levels. Without dutifully reporting on the number of integrated transgenes/mSOD1 expression levels, the issue is further compounded when independent groups attempt to replicate previous results. 


\section{Species differences and drug metabolism}

The incongruent findings between clinical and pre-clinical studies may further be explained by underlying physiological differences in metabolizing the therapeutic. To the authors' knowledge, no investigation has yet been conducted to study whether any putative ALS pharmacological agent is processed similarly in both mice and man, and thus whether it is bioactive to the same degree in these different species. Although it is used to induce a form of parkinsomism, systemic administration of the neurotoxic agent MPTP exemplifies species-specific differences in metabolic activity (87). In humans and primate models, intravenous delivery mediates an acute parkinsonian syndrome virtually indistinguishable from idiopathic Parkinson's disease. Rodent models however have proven to be somewhat more resilient to the toxic insult accompanying systemic administration. In rats, because of peripheral enzymatic catabolism of MPTP by monoamine oxidase, the polar MPP+ metabolite cannot cross the blood-brain-barrier and thus fails to selectively induce dopaminergic neuron degeneration (87). Without dutifully assessing the possibility of cross-species drug metabolic differences, it is possible that any pre-clinical effect may not be fully recapitulated in the clinic.

Future considerations for modeling disease and testing clinically-relevant ALS therapeutics

Due to the definitive need for therapeutics targeting the neurodegenerative cascade(s) inherent to ALS pathogenesis, it is of crucial importance that non-productive research endeavours are expediently identified and resources redirected to more promising avenues. To date, the reductionist approach of understanding ALS as a mSOD1mediated insult has not borne out an effective treatment strategy as was initially expected. In contrast to the current approach of studying potential therapeutics in the context of a specific genetic causality, a disease such as ALS with a complex etiology necessitates a multi-pronged strategy. Herein we broadly consider future strategies that could greatly facilitate the development and testing of potential ALS therapies.
Clinically-relevant biomarkers: assessing disease progression and therapeutic efficacy

There is a desperate need for the development of clinically-relevant biomarkers that will not only aid in an earlier diagnosis of disease, but also provide information with regard to disease progression. To date, various potential peripheral blood biomarkers have been identified, but none have been successfully translated into clinical use (reviewed in 88). Identification of such biomarkers would not only aid in diagnosing patients at an earlier stage of the disease, but also provide for an alternate measure of the effectiveness of any putative therapeutic agents.

Having a distinct correlative marker of disease progression might also shorten clinical trials since the effectiveness of a drug could be more efficiently assessed (88, 89). With shorter clinical trials, patients could then participate in more studies, thus allowing for more therapeutics to be clinically assessed and a treatment regimen to be fast-tracked. In addition, predictive biomarkers would allow for an earlier diagnosis of disease. This could facilitate an earlier intervention strategy in the progressive neurodegenerative cascade and theoretically mitigate additional CNS damage.

Blood provides for an easily-obtained biological fluid which constitutes a viable source for biomarker discovery, with the added caveat that blood biomarkers may not directly correlate with motor neuron degeneration (88). As Robelin and De Aguilar discuss, both the blood-brain barrier and the blood-cerebrospinal fluid barrier may act as an impediment to the crossing of relevant biomarkers into systemic circulation (88). There is thus a possibility that surrogate peripheral biomarkers may not adequately reflect the underlying degenerative cascade, or provide a direct measure of the intended therapeutic effect within the CNS. On account of the complex neurodegenerative cascade at play during ALS pathogenesis, it may be more appropriate to identify panels of biomarkers that clearly distinguish ALS from related disorders (88). 
A recently conducted clinical trial of rasagiline, an inhibitor of monoamine oxidase $\mathrm{B}$, demonstrates the application of potential blood biomarkers in assessing the clinical outcome of a therapeutic agent (90). Prior work had demonstrated that the drug had specific beneficial effects on mitochondrial function, decreased oxidative damage, and inhibited apoptosis. As previously pointed out, mitochondrial dysfunction is a clinical hallmark of ALS pathogenesis. Thus measuring particular biomarkers related to mitochondrial function (e.g. changes in mitochondrial membrane potential, oxidative stress, and the relative abundance of pro-survival/proapoptotic signals) may allow for a biochemically-relevant measure of therapeutic effectiveness in ALS clinical trials (90). The trial did not demonstrate an improvement in the functional ALSFRS-R scores after 12 months compared to historical controls (when corrected for symptom duration). However, peripheral lymphocytes showed evidence of an increased mitochondrial membrane potential, decreased oxidative stress, and an increased Bcl-2: Bax ratio; indicative of prosurvival cell signaling. A major caveat to the use of peripheral biomarkers as a surrogate indicator for activity within the CNS is the degree to which the therapeutic agent is able to penetrate, and act on cells within the CNS. In the case of rasagiline, the use of a peripheral mitochondrial biomarker is expected to be an adequate indicator of CNS activity since the therapeutic agent has demonstrated peripheral distribution and CNS penetration (90).

Development of alternate models to more effectively mirror the diverse etiological factors that underlie ALS pathogenesis

A critical problem lies in developing animal models which are more representative of ALS patients. To date, primarily on account of the unknown etiology, there is a lack of models that are representative of the sporadic form of the disease. Our group has previously investigated the dietary administration of cycad flour or extracted sterol glucosides as causative agents in the purported disease cascade (91-93), while others have assessed low Calcium/Magnesium, high Aluminum diets (94). Potential therapeutics have yet to be formally investigated within the context of these environmental model systems. Furthermore, there needs to be a renewed effort to develop and validate additional animal models with suspected environmental etiological factors.

On account of our increased understanding of the underlying genetic causal factors at play in ALS (Figure 1), there have been multiple additional murine models developed since the advent of the mutant SOD1 mouse. These include mice expressing mutant TDP-43 or the C9ORF72associated hexanucleotide repeat expansions (95-97). Characterising these additional systems allow for a more representative model of the overall ALS population as it takes into account the multiple underlying pathological changes that are implicated in disease pathogenesis.

However, a central caveat to conducting preclinical studies in animal models is the inability to rapidly screen multiple therapeutic agents in a single assay. To address this, an approach involves modeling the disease with nerve cells derived from induced pluripotent stem cells from sALS and/or fALS patients $(98,99)$. Not only could this strategy allow for the screening of a plethora of neuroprotective compounds, but it may pave the way for determining patient-specific drug responses to ALS therapeutics. An alternate approach employs the use of small invertebrate and vertebrate model systems expressing mutant forms of loci associated with ALS as platforms for pre-clinical drug development. Zebrafish and Caenorhabditis elegans animal models that express mutant forms of human TDP-43 or FUS allow for the production of large numbers of animals that can be housed in multi-well plates, tested with an array of potential therapeutic compounds, and assessed whether the disease phenotype is attenuated (100). Strategies such as these may allow for the rapid identification of potential therapeutic agents that can ultimately be applied at the clinical level.

Realistically, due to the heterogeneity of the pathological mechanism(s) at play, it is quite unlikely that any one model would be sufficient in mimicking all of the relevant underlying pathobiology. What should be 
adopted instead is a multi-pronged approach where a potential therapeutic is validated in multiple model systems testing specific outcomes prior to clinical translation. Adopting this strategy would enhance the likelihood of success since a treatment with positive outcomes in multiple model systems will be of greater relevance to the heterogeneous patient population.

Clinical trials should be designed and stratified so that the therapeutic effect of any agent is tested in a patient subset that is homologous for set criteria

Clinical ALS trials should be conducted in a manner that reflects the pathobiological heterogeneity underlying the neurodegenerative cascade. As discussed elsewhere, current evidence suggests that the disease presents along a continuum which ranges from "pure" ALS to frontotemporal dementia (6, 101). Employing a heterogeneous study population in a clinical trial with undefined disease mechanisms will not see positive outcomes unless all disease pathways converge for the ultimate phenotypic expression. It is possible that this may not be the case in ALS. That said, stratifying patient cohorts based on both the underlying causal mechanism(s) and degree of disease progression (i.e. due to validated biomarkers), would allow clinical researchers to develop targeted strategies that address definite causal mechanisms within a specific context.

\section{Conclusion}

We have reviewed that the most commonly used animal model in pre-clinical ALS therapeutic development is only representative of a small proportion of clinical cases, and has been shown to be a poor predictor of clinical success. To date, Riluzole is the only FDA-approved therapeutic, but one which has only a modest effect on overall lifespan and disease progression. All other therapeutics with positive pre-clinical outcomes in the murine model have not successfully translated to the clinical setting. The reasons for this are multifaceted in nature and not limited to a publication bias against negative preclinical data, a lack of reproducibility between research groups, a reductionist paradigm in pre-clinical testing, and a patient population affected by potentially multiple causal factors. As our understanding of the complex etiological factors in ALS evolves over the coming years, we can investigate multiple therapeutic compounds acting on diverse disease mechanisms and perhaps more effectively intervene in a large proportion of the affected populace.

\section{Conflict of Interest}

CAS is the Co-founder of Neurodyn Inc.

\section{Acknowledgement}

The authors thank the Luther Allyn Shrouds Dean Estate for their support.

\section{References}

1. Chiò A, Logroscino G, Traynor BJ, Collins J, Simeone JC, Goldstein LA, White LA. Global epidemiology of amyotrophic lateral sclerosis: a systematic review of the published literature. Neuroepidemiology 2013; 41(2): 118-130.

http://dx.doi.org/10.1159/000351153

PMid:23860588 PMCid:PMC4049265.

2. Byrne S, Walsh C, Lynch C, Bede P, Elamin M, Kenna K, McLaughlin R, Hardiman O. Rate of familial amyotrophic lateral sclerosis: a systematic review and meta-analysis. J Neurol Neurosurg Psychiatry 2011; 82: 623-7.

http://dx.doi.org/10.1136/jnnp.2010.224

$\underline{501}$

PMid:2 1047878.

3. Harms M, Baloh R. Clinical Neurogenetics. Neurol Clin 2013; 31: 929950.

http://dx.doi.org/10.1016/j.ncl.2013.05.0 $\underline{03}$ PMid:24176417 PMCid:PMC3815699.

4. Marangi G, Traynor BJ. Genetic causes of amyotrophic lateral sclerosis: new genetic analysis methodologies entailing new opportunities and challenges. Brain Res 2015; 1607: 75-93.

http://dx.doi.org/10.1016/j.brainres.2014 .10 .009

PMid:25316630. 
5. Amyotrophic Lateral Sclerosis Online Genetic Database (ALSOD).

http://alsod.iop.kcl.ac.uk/Overview/gene. aspx?gene_id=SOD1

6. Turner MR et al. Controversies and priorities in amyotrophic lateral sclerosis. Lancet Neurol 2013; 12: 310-322.

http://dx.doi.org/10.1016/S14744422(13)70036-X

7. Kabashi E, Valdmanis PN, Dion P, Rouleau GA. Oxidized/misfolded superoxide dismutase-1: the cause of all amyotrophic lateral sclerosis? Ann Neurol 2007; 62: 553559.

http://dx.doi.org/10.1002/ana.21319

PMid:18074357.

8. Bowling AC, Schulz JB, Brown RH. Superoxide dismutase activity, oxidative damage, and mitochondrial energy metabolism in familial and sporadic amyotrophic lateral sclerosis. J. Neurochem 1993; 61(6): 2322-2325.

http://dx.doi.org/10.1111/j.1471-

4159.1993.tb07478.x

9. Liu H-N, Sanelli T, Horne P, Pioro E, Strong M, Rogaeva E, Bilbao J, Zinman L, Robertson J. Lack of evidence of monomer/misfolded superoxide dismutase1 in sporadic amyotrophic lateral sclerosis. Ann Neurol 2009; 66: 75-80.

http://dx.doi.org/10.1002/ana.21704

PMid: 19670443.

10. Ayers J, Xu G, Pletnikova O, Troncoso J, Hart J, Borchelt D. Conformational specificity of the C4F6 SOD1 antibody; low frequency of reactivity in sporadic ALS cases. Acta Neuropathol Commun 2014; 2(55): 1-13.

http://dx.doi.org/10.1186/2051-5960-2$\underline{55}$

11. Pokrishevsky E, Grad LI, Yousefi M, Wang J, Mackenzie IR, Cashman NR. Aberrant localization of FUS and TDP43 is associated with misfolding of SOD1 in amyotrophic lateral sclerosis. PLoS ONE 2012; 7(4): 1-9.

http://dx.doi.org/10.1371/journal.pone.00 35050

PMid:22493728 PMCid:PMC3320864.
12. Rotunno MS, Bosco DA. An emerging role for misfolded wild-type SOD1 in sporadic ALS pathogenesis. Front Cell Neurosci 2013; 7: 1-16.

http://dx.doi.org/10.3389/fncel.2013.002

$\underline{53}$

PMid:24379756 PMCid:PMC3863749.

13. Mackenzie I et al. Pathological TDP-43 distinguishes sporadic amyotrophic lateral sclerosis from amyotrophic lateral sclerosis with SOD1 mutations. Ann Neurol 2007; 61: 427-434.

http://dx.doi.org/10.1002/ana.21147

PMid:17469116.

14. Shan X, Vocadlo D, Krieger C. Mislocalization of TDP-43 in the G93A mutant SOD1 transgenic mouse model of ALS. Neurosci Lett 2009; 458: 70-74.

http://dx.doi.org/10.1016/j.neulet.2009.0 4.031

PMid:19379791.

15. Turner BJ, Bäumer D, Parkinson NJ, Scaber J, Ansorge O, Talbot K. TDP-43 expression in mouse models of amyotrophic lateral sclerosis and spinal muscular atrophy. BMC Neurosci 2008; 9(104): 1-11. http://dx.doi.org/10.1186/1471-2202-9$\underline{104}$

16. Rosen $\mathrm{D}$ et al. Mutations in $\mathrm{Cu} / \mathrm{Zn}$ superoxide dismutase gene are associated with familial amyotrophic lateral sclerosis. Nature 1993; 362: 59-62.

http://dx.doi.org/10.1038/362059a0 PMid:8446170.

17. Gurney $\mathrm{M}, \mathrm{Pu} \mathrm{H}$, Chiu A, Canto M, Polchow C, Alexander D, Caliendo J, Hentati A, Kwon Y, Deng H. Motor neuron degeneration in mice that express a human $\mathrm{Cu}, \mathrm{Zn}$ superoxide dismutase mutation. Science 1994; 264: 1772-1775.

http://dx.doi.org/10.1126/science.820925 $\underline{8}$

PMid:8209258.

18. Wong P, Pardo C, Borchelt D, Lee M, Copeland N, Jenkins N, Sisodia S, Cleveland D, Price D. An adverse property of a familial ALS-linked SOD1 mutation causes motor neuron disease characterized by vacuolar degeneration of mitochondria. Neuron 1995; 14: 1105-1116. 
http://dx.doi.org/10.1016/0896$\underline{\text { 6273(95)90259-7 }}$

19. Mitsumoto H, Brooks BR, Silani V. Clinical trials in amyotrophic lateral sclerosis: why so many negative trials andhow can trials be improved? Lancet Neurol 2014; 13: 1127-1138.

http://dx.doi.org/10.1016/S14744422(14)70129-2

20. Dal Canto D, Gurney ME. Development of central nervous system pathology in a murine transgenic model of human amyotrophic lateral sclerosis. Am J Pathol 1994; 145(6): 1271-1279.

PMid:7992831 PMCid:PMC1887498.

21. Dal Canto MC, Gurney ME. Neuropathological changes in two lines of mice carrying a transgene for mutant human $\mathrm{Cu}, \mathrm{Zn} \mathrm{SOD}$, and in mice overexpressing wild type human SOD: a model of familial amyotrophic lateral sclerosis (FALS). Brain Res 1995; 676: 2540.

http://dx.doi.org/10.1016/00068993(95)00063-V

22. Gurney ME. The use of transgenic mouse models of amyotrophic lateral sclerosis in preclinical drug studies. J Neurol Sci 1997; 152(Suppl. 1): S67-S73.

23. Jonsson PA, Graffmo KS, Brännström T, Nilsson P, Andersen PM, Marklund SL. Motor neuron disease in mice expressing the wild type-like D90A mutant superoxide dismutase-1. J Neuropathol Exp Neurol 2006; 65(12): 1126-1136.

http://dx.doi.org/10.1097/01.jnen.000024 $8545.36046 .3 \mathrm{c}$

PMid:17146286.

24. Bruijn LI, Becher MW, Lee MK, Anderson KL, Jenkins NA, Copeland NG, Sisodia SS, Rothstein JD, Borchelt DR, Price DL, Cleveland DW. ALS-Linked SOD1 Mutant G85R Mediates Damage to Astrocytes and Promotes Rapidly Progressive Disease with SOD1-Containing Inclusions. Neuron 1997; 18: 327-338.

http://dx.doi.org/10.1016/S08966273(00)80272-X

25. Kato S. Amyotrophic lateral sclerosis models and human neuropathology: similarities and differences. Acta Neuropathol 2007; 115: 97-114. http://dx.doi.org/10.1007/s00401-0070308-4 PMid: 18026741.

26. Van Den Bosch L. Genetic Rodent Models of Amyotrophic Lateral Sclerosis. J Biomed Biotechnol 2011; 1-11. http://dx.doi.org/10.1155/2011/348765 PMid:21274268 PMCid:PMC3022221.

27. Saccon RA, Bunton-Stasyshyn RKA, Fisher EMC, Fratta P. Is SOD1 loss of function involved in amyotrophic lateral sclerosis? Brain 2013; 136: 2342-2358.

http://dx.doi.org/10.1093/brain/awt097 PMid:23687121 PMCid:PMC3722346.

28. Benatar M. Lost in translation: treatment trials in the SOD1 mouse and in human ALS. Neurobiol Dis 2007; 26: 1-13. http://dx.doi.org/10.1016/j.nbd.2006.12. $\underline{015}$

PMid:17300945.

29. Hall ED, Oostveen JOA, Gurney ME. Relationship of microglial and astrocytic activation to disease onset and progression in a transgenic model of familial ALS. Glia 1998; 23: 249-256.

http://dx.doi.org/10.1002/(SICI)1098-

1136(199807)23:3<249::AID-

GLIA7>3.0.CO;2-\#

30. Lewis KE, Rasmussen AL, Bennett W, King A. Microglia and motor neurons during disease progression in the SOD1G93A mouse model of amyotrophic lateral sclerosis:changes in arginase 1 and inducible nitric oxide synthase. $\mathrm{J}$ Neuroinflamm 2014; 11: 55

http://dx.doi.org/10.1186/1742-2094-11$\underline{55}$

PMid:24655927 PMCid:PMC3994340.

31. Boillée S, VandeVelde C, Cleveland DW. ALS: A Disease of motor neurons and their nonneuronal neighbors. Neuron 2006; 52: 39-59.

http://dx.doi.org/10.1016/j.neuron.2006. $\underline{09.018}$

PMid:17015226.

32. Alexianu ME, Kozovska M, Appel SH. Immune reactivity in a mouse model of familial ALS correlates with disease 
progression. Neurology 2001; 57: 12821289.

http://dx.doi.org/10.1212/WNL.57.7.1282 PMid:11591849.

33. Wilkins HM, Bouchard RJ, Lorenzon NM, Linseman DA. Poor correlation between drug efficacies in the mutant SOD1 mouse model versus clinical trials of ALS necessitates the development of novel animal models for sporadic motor neuron disease. In: Costa A, and Villalba E, eds. Horizons in Neuroscience Research Vol 5. Nova Science Publishers, New York: 2011; 1-39.

34. Danbolt NC. Glutamate uptake. Prog Neurobiol 2001; 65: 1-105.

http://dx.doi.org/10.1016/S0301$\underline{0082(00) 00067-8}$

35. Julien J-P. Amyotrophic Lateral Sclerosis: Unfolding the Toxicity of the Misfolded. Cell 2001; 104: 581-591. http://dx.doi.org/10.1016/S00928674(01)00244-6

36. Zhivotovsky B, Orrenius S. Calcium and cell death mechanisms: a perspective from the cell death community. Cell Calcium 2011; 50: 211-221.

http://dx.doi.org/10.1016/j.ceca.2011.03. $\underline{003}$

PMid:2 1459443.

37. Jaiswal M, Zech W-D, Goos M, Leutbecher C, Ferri A, Zippelius A, Carrì M, Nau R, Keller B. Impairment of mitochondrial calcium handling in a mtSOD1 cell culture model of motoneuron disease. BMC Neurosci 2009; 10: 64. http://dx.doi.org/10.1186/1471-2202-1064

PMid:19545440 PMCid:PMC2716351.

38. Plaitakis A, Constantakakis E. Altered metabolism of excitatory amino acids, Nacetyl-aspartate and N-acetyl-aspartylglutamate in amyotrophic lateral sclerosis. Brain Res Bull 1993; 30: 381-386. http://dx.doi.org/10.1016/03619230(93)90269-H

39. Camu W, Billiard M, Baldy-Moulinier M. Fasting plasma and CSF amino acid levels in amyotrophic lateral sclerosis: a subtype analysis. Acta Neurol Scand 1993; 88: 5155.

http://dx.doi.org/10.1111/j.1600-

0404.1993.tb04186.x

PMid:8372631.

40. Rothstein JD, Martin LJ, Kuncl RW. Decreased glutamate transport by the brain and spinal cord in amyotrophic lateral sclerosis. N Engl J Med 1992; 326(22): 1464-1468.

http://dx.doi.org/10.1056/NEJM1992052 83262204

PMid:1349424.

41. Miller RG, JD M, Moore DH. Riluzole for amyotrophic lateral sclerosis (ALS)/motor neuron disease (MND). Cochrane Database of Syst Rev 2012; CD001447.

PMid:22419278

42. Azbill RD, Mu X, Springer JE. Riluzole increases high-affinity glutamate uptake in rat spinal cord synaptosomes. Brain Res 2000; 871: 175-180.

http://dx.doi.org/10.1016/S00068993(00)02430-6

43. Wang S-J, Wang K-Y, Wang W-C. Mechanisms underlying the riluzole inhibition of glutamate release from rat cerebral cortex nerve terminals (synaptosomes). Neurosci 2004; 125: 191201.

http://dx.doi.org/10.1016/j.neuroscience. 2004.01.019

PMid:15051158.

44. Bensimon G, Lacomblez L, Meininger V. A controlled trial of riluzole in amyotrophic lateral sclerosis. N Engl J Med 1994: 330(9): 585-591.

http://dx.doi.org/10.1056/NEJM1994030 33300901

PMid:8302340.

45. Lacomblez L, Bensimon G, Leigh PN, Guillet P, Powe L, Durrleman S, Delumeau JC, Meininger V. A confirmatory doseranging study of riluzole in ALS. Neurology 1996; 47 (Suppl 4): S242-S250.

http://dx.doi.org/10.1212/WNL.47.6_Sup pl 4.242S

PMid:8959996.

46. Lacomblez L, Bensimon G, Leigh PN, Guillet $P$, Meininger V. Dose-ranging study 
of riluzole in amyotrophic lateral sclerosis. Lancet 1996; 347: 1425-1431. http://dx.doi.org/10.1016/S0140$\underline{6736(96) 91680-3}$

47. Traynor BJ, Alexander M, Corr B, Frost E, Hardiman, O. An outcome study of riluzole in amyotrophic lateral sclerosis. J Neurol 2003; 250: 473-479.

http://dx.doi.org/10.1007/s00415-0031026-Z

PMid:12700914.

48. Zoccolella S, Beghi E, Palagano G. Riluzole and amyotrophic lateral sclerosis survival: a population-based study in southern Italy. Eur J Neurol 2007; 14: 262268.

http://dx.doi.org/10.1111/j.14681331.2006.01575.x

PMid:17355545.

49. Gurney ME, Cutting FB, Zhai P, Doble A, Taylor, CP, Andrus PK, Hall ED. Benefit of vitamin $\mathrm{E}$, riluzole, and gababapentin in a transgenic model of familial amyotrophic lateral sclerosis. Ann Neurol 1996; 39(2): 147-157.

http://dx.doi.org/10.1002/ana.410390203 PMid:8967745.

50. Gurney ME, Fleck TJ, Himes CS, Hall ED. Riluzole preserves motor function in a transgenic model of familial amyotrophic lateral sclerosis. Neurol 1998; 50: 62-66. http://dx.doi.org/10.1212/WNL.50.1.62

51. Yrjänheikki J, Keinänen R, Pellikka M, Hökfelt T, Koistinaho J. Tetracyclines inhibit microglial activation and are neuroprotective in global brain ischemia. Proc Natl Acad Sci 1998; 95:15769-15774. http://dx.doi.org/10.1073/pnas.95.26.157 69

PMid:9861045 PMCid:PMC28119.

52. Yrjänheikki J, Tikka T, Keinänen R, Goldsteins G, Chan PH, Koistinaho J. A tetracycline derivative, minocycline, reduces inflammation and protects against focal cerebral ischemia with a wide therapeutic window. Proc Natl Acad Sci 1999; 96(23): 13496-13500.

http:/ / dx.doi.org/10.1073/pnas.96.23.134 96

PMid:10557349 PMCid:PMC23976.
53. Henkel JS, Beers DR, Zhao W, Appel SH. Microglia in ALS: the good, the bad, and the resting. J Neuroimmune Pharmacol 2009; 4: 389-398.

http: / /dx.doi.org/10.1007/s11481-009-

9171-5

PMid:19731042.

54. Kriz J, Nguyen MD, Julien JP. Minocycline slows disease progression in a mouse model of amyotrophic lateral sclerosis. Neurobiol Dis 2002; 10: 268-278. http://dx.doi.org/10.1006/nbdi.2002.048 $\underline{7}$ PMid:12270689.

55. Van Den Bosch L, Tilkin P, Lemmens G, Robberecht W. Minocycline delays disease onset and mortality in a transgenic model of ALS. NeuroReport 2002; 13(8): 1067-1070. http://dx.doi.org/10.1097/00001756200206120-00018

PMid:12060810.

56. Zhu $\mathrm{S}$ et al. Minocycline inhibits cytochrome c release and delays progression of amyotrophic lateral sclerosis in mice. Nature 2002; 417: 74-78.

http:/ /dx.doi.org/10.1038/417074a

PMid:11986668.

57. Gordon PH, Moore DH, Gelinas DF, Qualls C, Meister ME, Werner J, Mendoza M, Mass J,Kushner G, Miller RG. Placebocontrolled phase I/II studies of minocycline in amyotrophic lateral sclerosis. Neurology 2004; 62: 1845-1847.

http://dx.doi.org/10.1212/01.WNL.00001 25321.92112.7E

PMid:15159491.

58. Pontieri FE, Ricci A, Pellicano C, Benincasa D, Buttarelli FR. Minocycline in amyotrophic lateral sclerosis: a pilot study. Neurol Sci 2005; 26: 285-287. http://dx.doi.org/10.1007/s10072-0050474-X

PMid:16193258.

59. Gordon PH et al. Efficacy of minocycline in patients with amyotrophic lateral sclerosis: a phase III randomised trial. Lancet Neurol 2007; 6: 1045-1053. http://dx.doi.org/10.1016/S14744422(07)70270-3 
60. Shi P, Gal J, Kwinter D, Liu X, Zhu H. Mitochondrial dysfunction in amyotrophic lateral sclerosis. Biochim Biophys Acta 2010; 1802(1): 45-51.

http://dx.doi.org/10.1016/j.bbadis.2009.0 8.012

PMid:19715760 PMCid:PMC2790551.

61. Carrì MT, Ferri A, Battistoni A, Famhy L, Gabbianelli R, Poccia F, Rotilio G. Expression of a $\mathrm{Cu}, \mathrm{Zn}$ superoxide dismutase typical of familial amyotrophic lateral sclerosis induces mitochondrial alteration and increase of cytosolic $\mathrm{Ca} 2+$ concentration in transfected neuroblastoma SH-SY5Y cells. FEBS Lett 1997; 414: 365368.

http://dx.doi.org/10.1016/S0014$\underline{\text { 5793(97)01051-X }}$

62. Kruman II, Pedersen WA, Springer JE, Mattson MP. ALS-linked $\mathrm{Cu} / \mathrm{Zn}$-SOD mutation increases vulnerability of motor neurons to excitotoxicity by a mechanism involving increased oxidative stress and perturbed calcium homeostasis. Exp Neurol 1999; 160: 28-39.

http://dx.doi.org/10.1006/exnr.1999.7190 PMid:10630188.

63. Sasaki S, Iwata M. Ultrastructural study of synapses in the anterior horn neurons of patients with amyotrophic lateral sclerosis. Neurosci Lett 1996; 204: 53-56.

http://dx.doi.org/10.1016/03043940(96)12314-4

64. Wallimann T, Hemmer W. Creatine kinase in non-muscle tissues and cells. Mol Cell Biochem 1994; 133/134: 193-220. http://dx.doi.org/10.1007/BF01267955

65. Groeneveld GJ, Veldink JH, van der Tweel I, Kalmijn S, Beijer C, de Visser M, Wokke JHJ, Franssen H, van den Berg LH. A randomized sequential trial of creatine in amyotrophic lateral sclerosis. Ann Neurol 2003; 53:437-445.

http://dx.doi.org/10.1002/ana.10554

PMid:12666111.

66. Brewer GJ, Wallimann TW. Protective effect of the energy precursor creatine against toxicity of glutamate and betaamyloid in rat hippocampal neurons. $J$ Neurochem 2000; 74(5):1968-1978. http://dx.doi.org/10.1046/j.1471-

4159.2000.0741968.x

PMid:10800940.

67. Lawler JM, Barnes WS, Wu G, Song W, Demaree S. Direct antioxidant properties of creatine. Biochem Biophys Res Commun 2002; 290: 47-52.

http://dx.doi.org/10.1006/bbrc.2001.616 4

PMid:11779131.

68. Wendt S, Dedeoglu A, Speer O, Wallimann T, Beal MF, Andreassen OA. Reduced creatine kinase activity in transgenic amyotrophic lateral sclerosis mice. Free Radic Biol Med 2002; 32(9): 920926.

http://dx.doi.org/10.1016/S0891$\underline{\text { 5849(02)00784-0 }}$

69. Dolder $M$, Wendt $S$, Wallimann $T$. Mitochondrial creatine kinase in contact sites: interaction with porin and adenine nucleotide translocase, role in permeability transition and sensitivity to oxidative damage. Biol Signals Recept 2001; 10: 93111.

http://dx.doi.org/10.1159/000046878

PMid:1 1223643.

70. Klivenyi P, Ferrante RJ, Matthews RT, Bogdanov MB, Klein AM, Andreassen OA, Mueller G, Wermer M, Kaddurah-Daouk R, Beal MF. Neuroprotective effects of creatine in a transgenic animal model of amyotrophic lateral sclerosis. Nature Med 1999; 5(3): 347-350.

http://dx.doi.org/10.1038/6568

PMid:10086395.

71. Snow RJ, Turnbull J, Silva DS, Jiang F. Creatine supplementation and riluzole treatment provide similar beneficial effects in copper, zinc superoxide dismutase (G93A) transgenic mice. Neurosci 2003; 119: 661-667.

http://dx.doi.org/10.1016/S03064522(03)00212-4

72. Zhang W, Narayanan M, Friedlander RM. Additive neuroprotective effects of minocycline with creatine in a mouse model of ALS. Ann Neurol 2003; 53:267-270.

http://dx.doi.org/10.1002/ana.10476

PMid:12557297. 
73. Shefner JM et al. A clinical trial of creatine in ALS. Neurol 2004; 63: 16561661.

http://dx.doi.org/10.1212/01.WNL.00001 42992.81995.FO

74. Rosenfeld J, King RM, Jackson CE, Bedlack RS, Barohn RJ, Dick A, Phillips LH, Chapin J, Gelinas DF, Lou J-S. Creatine monohydrate in ALS: Effects on strength, fatigue, respiratory status and ALSFRS. Amyotroph Lateral Sc 2008; 9: 266-272. http://dx.doi.org/10.1080/174829608020 28890

PMid:18608103 PMCid:PMC2631354.

75. Ravits J et al. Deciphering amyotrophic lateral sclerosis: what phenotype, neuropathology and genetics are telling us about pathogenesis. Amyotroph Lateral Scler Frontotemporal Degener 2013; 14(Suppl 1): 5-18.

http://dx.doi.org/10.3109/21678421.2013 .778548

PMid:23678876 PMCid:PMC3779649.

76. Beghi E et al. The epidemiology and treatment of ALS: Focus on the heterogeneity of the disease and critical appraisal of therapeutic trials. Amyotrophic Lateral Sclerosis 2011; 12: 1-10.

http://dx.doi.org/10.3109/17482968.2010 .502940

PMid:20698807 PMCid:PMC3513399.

77. Hackam D, Redelmeier D. Translation of Research Evidence From Animals to Humans. J Am Med Assoc 2006; 296(14): 1731-1732.

http://dx.doi.org/10.1001/jama.296.14.17 31

PMid: 17032985.

78. Seok $\mathrm{J}$ et al. Genomic responses in mouse models poorly mimic human inflammatory diseases. Proc Natl Acad Sci 2013; 110(9): 3507-3512.

http://dx.doi.org/10.1073/pnas. 12228781 $\underline{10}$

PMid:23401516 PMCid:PMC3587220.

79. Scott $\mathrm{S}$ et al. Design, power, and interpretation of studies in the standard murine model of ALS. Amyotroph Lateral Sc 2008; 9: 4-15.

http://dx.doi.org/10.1080/174829607018 $\underline{56300}$
PMid:18273714

80. Dal Canto MC, Gurney ME. A low expressor line of transgenic mice carrying a mutant human $\mathrm{Cu}, \mathrm{Zn}$ superoxide dismutase (SOD1) gene developes pathological changes that most closely resemble those in human amyotrophic lateral sclerosis. Acta Neuropathol 1997; 93(6): 537-550.

http://dx.doi.org/10.1007/s00401005065 $\underline{0}$

81. Saeed M, Yang Y, Deng H-X, Hung W-Y, Siddique N, Dellafave L, Gellera C, Andersen PM, Siddique T. Age and founder effect of SOD1 A4V mutation causing ALS. Neurol 2009; 72: 1634-1639.

http://dx.doi.org/10.1212/01.wnl.000034 3509.76828.2a

PMid:19176896 PMCid:PMC2683645.

82. Deng $\mathrm{H}-\mathrm{X}$ et al. Conversion to the amyotrophic lateral sclerosis phenotype is associated with intermolecular linked insoluble aggregates of SOD1 in mitochondria. Proc Natl Acad Sci 2006; 103(18): 7142-7147.

http://dx.doi.org/10.1073/pnas.06020461 $\underline{03}$

PMid:16636275 PMCid:PMC1447523.

83. Zwiegers P, Lee G, Shaw CA. Reduction in hSOD1 copy number significantly impacts ALS phenotype presentation in G37R (line 29) mice: implications for the assessment of putative therapeutic agents. J Neg Resul Biomed 2014; 13: 14. http://dx.doi.org/10.1186/1477-5751-1314

PMid:25103619 PMCid:PMC4134475.

84. Alexander G, Erwin K, Byers N, Deitch JS, Augelli BJ, Blankenhorn EP, HeimanPatterson TD. Effect of transgene copy number on survival in the G93A SOD1 transgenic mouse model of ALS. J Mol Brain Res 2004; 130: 7-15.

http://dx.doi.org/10.1016/j.molbrainres.2 004.07.002

PMid:15519671.

85. Chiu AY, Zhai P, Dal Canto MC, Peters TM, Kwon YW, Prattis SM, Gurney ME. Agedependent penetrance of disease in a 
transgenic mouse model of familial amyotrophic lateral sclerosis. Mol Cell Neurosci 1995; 6: 349-362.

http://dx.doi.org/10.1006/mcne.1995.102 7

PMid:8846004.

86. Zhang B, Tu P, Abtahian F, Trojanowski JQ, Lee VM-Y. Neurofilaments and orthograde transport are reduced in ventral root axons of transgenic mice that express human SOD1 with a G93A mutation. J Cell Biol 1997; 139(5): 1307-1315.

http://dx.doi.org/10.1083/jcb.139.5.1307 PMid:9382875 PMCid:PMC2140205.

87. Kalaria RN, Mitchell MJ, Harik SI. Correlation of 1-methyl-4-phenyl-1,2,3,6tetrahydropyridine neurotoxicity with bloodbrain barrier monoamine oxidase activity. Proc Natl Acad Sci s 1987; 84: 3521-3525. http://dx.doi.org/10.1073/pnas.84.10.352 $\underline{1}$

88. Robelin L, Gonzalez De Aguilar JL. Blood Biomarkers for Amyotrophic Lateral Sclerosis: Myth or Reality? BioMed Res Intl 2014; 2014.

89. Ryberg H, Bowser R. Protein biomarkers for amyotrophic lateral sclerosis. Expert Rev Proteomics 2008; 5(2): 249-262.

http://dx.doi.org/10.1586/14789450.5.2.2 $\underline{49}$

PMid:18466055.

90. Macchi $Z$ et al. A multi-center screening trial of rasagiline in patients with amyotrophic lateral sclerosis: Possible mitochondrial biomarker target engagement. Amyotroph Lateral Scler Frontotemporal Degener 2015: 1-8.

http://dx.doi.org/10.3109/21678421.2015 .1026826

PMid:25832828.

91. Tabata RC, Wilson JMB, Ly P, Zwiegers P, Kwok D, Van Kampen JM, Cashman N, Shaw CA. Chronic Exposure to Dietary Sterol Glucosides is Neurotoxic to Motor Neurons and Induces an ALS-PDC Phenotype. Neuromol Med 2008; 10: 24-39. http://dx.doi.org/10.1007/s12017-0078020-z

PMid:18196479 PMCid:PMC2814814.
92. Schulz JD, Wilson J, Shaw CA. A Murine Model of ALS PDC with Behavioral and Neuropathological Features of Parkinsonism. Ann New York Acad Sci 2003; 991: 326-329.

http://dx.doi.org/10.1111/j.17496632.2003.tb07497.x

93. Wilson JMB et al. Behavioral and neurological correlates of ALS-parkinsonism dementia complex in adult mice fed washed cycad flour. Neuromol Med 2002; 207-22 1.

94. Kihira T, Yoshida S, Kondo T, Yase Y, Ono S. ALS-like skin changes in mice on a chronic low-Ca/Mg high-Al diet. J Neurol Sci 2004; 219: 7-14.

http://dx.doi.org/10.1016/j.jns.2003.11.0 10 PMid:15050431.

95. Wegorzewska I, Bell S, Cairns NJ. TDP43 mutant transgenic mice develop features of ALS and frontotemporal lobar degeneration. Proc Natl Acad Sci 2009; 106(44):18809-18814.

http://dx.doi.org/10.1073/pnas.09087671 $\underline{06}$ PMid:19833869 PMCid:PMC2762420.

96. Hukema $R$, Riemslagh $F$, Melhem $S$, Linde H, Severijnen L-A, Edbauer D, Maas A, Charlet-Berguerand $\mathrm{N}$, Willemsen $\mathrm{R}$, Swieten J. A new inducible transgenic mouse model for C9orf72-associated GGGGCC repeat expansion supports a gainof-function mechanism in C9orf72associated ALS and FTD. Acta Neuropathol Commun 2014; 2: 166.

http://dx.doi.org/10.1186/s40478-014$0166-\mathrm{y}$

PMid:25523491 PMCid:PMC4271461.

97. Chew $J$ et al. Neurodegeneration. C9ORF72 repeat expansions in mice cause TDP-43 pathology, neuronal loss, and behavioral deficits. Science 2015; 348(6239): 1151-4.

http://dx.doi.org/10.1126/science.aaa934 4

PMid:25977373.

98. Burkhardt MF et al. A cellular model for sporadic ALS using patient-derived induced pluripotent stem cells. Mol Cell Neurosci 2013; 56: 355-64. 
http://dx.doi.org/10.1016/j.mcn.2013.07. $\underline{007}$ PMid:23891805.

99. Richard J-P, Maragakis NJ. Induced pluripotent stem cells from ALS patients for disease modeling. Brain Res 2015; 1607: 15-25.

http://dx.doi.org/10.1016/j.brainres.2014 .09 .017

PMid:25223906.

100. Vaccaro A, Patten SA, Ciura S, Maios C, Therrien M, Drapeau P, Kabashi E, Parker JA. Methylene blue protects against TDP-43 and FUS neuronal toxicity in C. elegans and D. rerio. PLoS ONE 2012; 7: e42117.

http://dx.doi.org/10.1371/journal.pone.00 $\underline{42117}$

PMid:22848727 PMCid:PMC3407135.
101. Robberecht W, Philips T. The changing scene of amyotrophic lateral sclerosis. Nat Rev Neurosci 2013; 14(4): 248-264.

http://dx.doi.org/10.1038/nrn3430 PMid:23463272.

102. Ezzi S, Larivière $R$, Urushitani $M$, Julien J-P. Neuronal over-expression of chromogranin A accelerates disease onset in a mouse model of ALS. J Neurochem 2010; 115: 1102-1111.

http://dx.doi.org/10.1111/i.1471-

4159.2010.06979.x

PMid:20807312.

103. Nguyen $M$, Larivière $R$, Julien J-P. Deregulation of Cdk5 in a Mouse Model of ALS: Toxicity Alleviated by Perikaryal Neurofilament Inclusions. Neuron 2001; 30:135-147.

http:/ /dx.doi.org/10.1016/S0896-

6273(01)00268-9 